San Jose State University

SJSU ScholarWorks

Master's Projects

Master's Theses and Graduate Research

7-23-2004

\title{
The Prevalence of Dental Caries in a Central Coast of California \\ Middle School
}

Belen R. Mojica

San Jose State University

Follow this and additional works at: https://scholarworks.sjsu.edu/etd_projects

Part of the Pediatric Nursing Commons

\section{Recommended Citation}

Mojica, Belen R., "The Prevalence of Dental Caries in a Central Coast of California Middle School" (2004). Master's Projects. 793.

DOI: https://doi.org/10.31979/etd.pvcc-yqh7

https://scholarworks.sjsu.edu/etd_projects/793

This Master's Project is brought to you for free and open access by the Master's Theses and Graduate Research at SJSU ScholarWorks. It has been accepted for inclusion in Master's Projects by an authorized administrator of SJSU ScholarWorks. For more information, please contact scholarworks@sjsu.edu. 


\section{SAN JOSE STATE UNIVERSITY SCHOOL OF NURSING}

\section{MASTER'S PROGRAM PROJECT OPTION (PLAN B) PROJECT SIGNATURE FORM}

STUDENT NAME

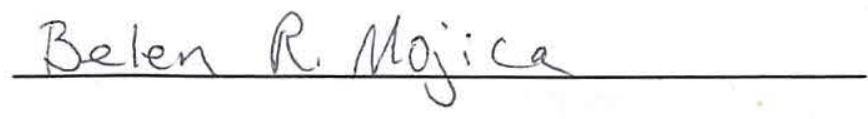

SEMESTER ENROLLED

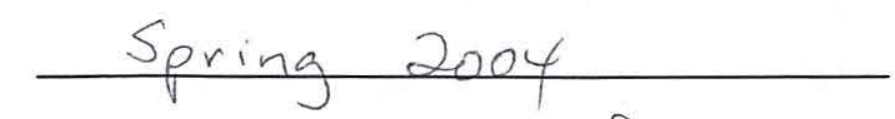

TITLE OF PROJECT The Prevalence of Dental Caries in a Cel. furnia Central Coast Middle School

\section{NAME OF JOURNAL}

\section{J. of School Nursing}

The project and the manuscript have been successfully completed and meet the standards of the School of Nursing University. The project demonstrates the application of professional knowledge, clinical expertise, and scholarly thinking. An abstract of the project and two copies of the manuscript are attached.

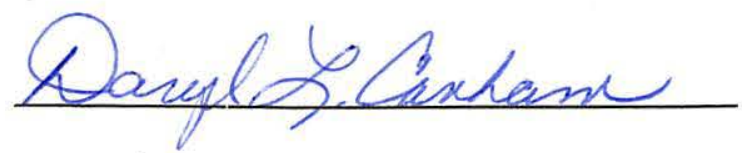

ADVISOR'S SIGNAURE

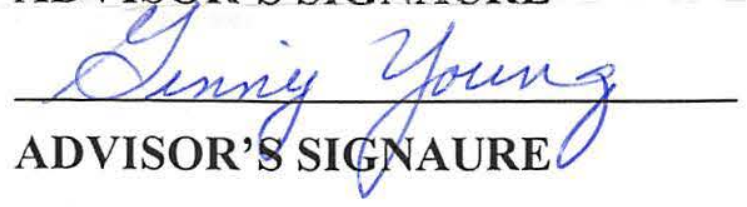

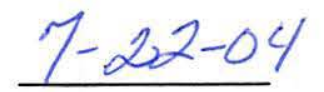

DATE

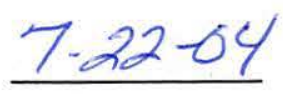

DATE

Please submit the form to the Graduate Coordinator. Attach abstract, two copies of the manuscript, and the documentation of submission to the journal (i.e., postal receipt). 


\section{THE PREVALENCE OF DENTAL CARIES IN A CENTRAL COAST OF CALIFORNIA MIDDLE SCHOOL}

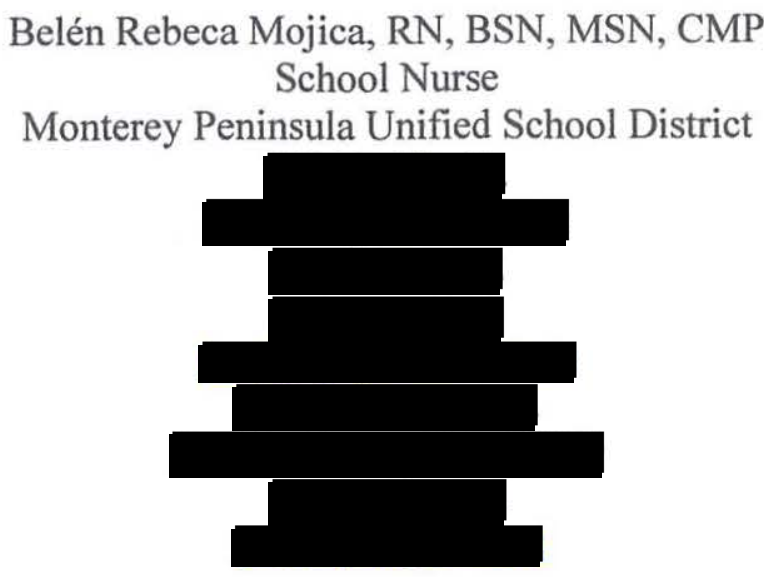

Daryl L. Canham, RNC, EdD Associate Professor San Jose State University School of Nursing 1 Washington Square San Jose, CA 95192-0057

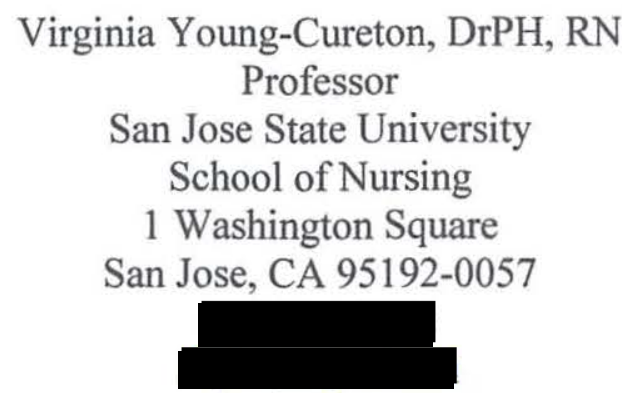

This manuscript reflects the final research project for completion of the Master of Science degree at San Jose State University, School of Nursing. Ms. Mojica was the primary author. Dr. Canham was the first advisor for the project and the manuscript. Dr. Young was the second advisor for the project and the manuscript. 
THE PREVALENCE OF DENTAL CARIES IN A CENTRAL COAST OF CALIFORNIA MIDDLE SCHOOL

\author{
A Research Project \\ Presented to \\ The Faculty of the School of Nursing \\ San Jose State University \\ In Partial Fulfillment \\ Of the Requirements for the Degree \\ Master of Science
}

by

Belen R. Mojica

July 23, 2004 
THE PREVALENCE OF DENTAL CARIES IN A CALIFORNIA CENTRAL COAST

MIDDLE SCHOOL

\begin{abstract}
Dental morbidity is a chronic problem that affects a child's ability to attend school, to learn, and to enjoy good health. Of all childhood diseases, oral disease ranks as one of the highest and is considered one of the most common and the least treated. The prevalence of dental caries is high among children and adolescents in school populations. This study explored the prevalence of dental caries in a California Central Coast middle school during the 2002-03 school year $(\mathrm{N}=526)$. Findings indicated that severe dental caries existed in both boys and girls and in students of various ethnic groups. Approximately $5.7 \%$ of adolescents were shown to have visible and severe dental caries with significant ethnic variation. Twice as many Hispanic teens had visible dental caries as the white and other non-white teens. School nurses should routinely screen for dental disease in all school grades and provide resources and referrals for dental treatment.
\end{abstract}

KEY WORDS: adolescents, dental health, chronic disease, ethnic variations 


\section{Introduction}

Dental morbidity is a chronic problem that affects a child's ability to attend school, to learn, and to enjoy good health. Of all childhood diseases, oral disease ranks at the top and is considered one of the most common and the least treated (Dental Health Foundation [DHF], 2001; Peterson, Niessen, \& Lopez, 1999). A diseased mouth significantly affects one's quality of life by causing pain, dysfunction in eating and speaking, underweight, poor appearance and can greatly reduce the chances of succeeding in life. Good oral health is an integral part of overall health but is often not considered an important component of total body health. Children in the United States [U.S.] are absent from school about fifty-one million hours per year due to dental pain and dental visits (Vargas, Ronzio, \& Hayes, 2003; Peterson et al.). The number of children reporting acute dental problems is approximately the same as the number reporting headaches or about 16 in 1000 persons in the United States (Peterson et al.). Adolescents are in a high-risk group for having unmet dental health needs. In a survey conducted by the National Longitudinal Study of Adolescent Health (NLSAH), findings revealed that approximately $32 \%$ of the teens had not visited a dentist in the year before the survey, and about $2 \%$ reported never having been to a dentist (Yu, Bellamy, Schwalberg, \& Drum, 2001).

Preventive treatment is less expensive and less serious than the treatment of a mouth full of dental caries. Untreated dental caries can reach an irreversible state and can lead to needless pain and suffering. Even though there has been an overall reduction in the number of children with dental caries in the past two decades, disparities still exist among certain segments of the population who continue to have unmet dental needs (U.S. Department of Health and Human Services [USDHHS], Healthy People 2010, 2000). Not having preventive care has been associated with lack of insurance, low family income, and little or no parental education (Yu, et al., 2001; Udry \& Bearman, 1998). Further, adolescent males, African-Americans, Hispanics, and teens of mixed race/ethnicity are also more likely to have infrequent dental visits. Children of parents with higher education levels had a lower mean number of decayed, missing, or filled surfaces (dmfs) than children of parents with lower education. 
Prevention is a major component of dental health. According to a fact sheet generated by the Centers for Disease Control (CDC, 2002), community water fluoridation has contributed to a significant improvement in the status of oral health by preventing dental caries. Children living in these communities have $29 \%$ fewer cavities. Dental sealants, when applied, can prevent disease for 2 to 5 years. Ohio was the first state to implement a state-funded, schoolbased dental sealant program in the 1980s. Twenty-nine states now have state and/or federally funded (Medicaid, grants, in-kind donations, local revenues) school-based dental sealant programs which target low income children, yet only $3 \%$ (approximately 193,000 children) of children who qualify and who need this service have received this preventive treatment (Morbidity and Mortality Weekly Report [MMWR], 2001; Amsler, 2003; CDC, 2002 \& Heneghan \& Malakoff, 1997).

The American Academy of Pediatric Dentistry (AAPD) now recommends annual dental visits for preventive care which would monitor the status of oral health and prevent disease by (a) applying dental sealants, (b) recommending fluoride rinses, (c) teeth-cleaning every six months by a dental hygienist, (d) teaching good oral hygiene habits, and (e) repairing minor caries before irreversible damage occurs. Watson, Manski, and Macek (2001), conducted a study on the impact of income at the "poor" and "near poor" levels on children's and adolescents" preventive dental visits. In the poor and near poor population there were less preventive dental visits but there were more visits for secondary prevention (treatment of early caries) and emergency dental visits. One of the objectives of Healthy People 2010 is to increase the number of preventive dental visits in those children and adolescents 19 years of age and under who fall at or below the poverty line (U.S. Department of Health and Human Services [USDHHS] Healthy People 2010, 2000).

The existing data reflect the serious dental needs of adolescents and children, and especially of those adolescents and children who live in families with incomes at the poor level, near poor level, or slightly above the poverty level. School nurses performing dental screenings can target students with visible dental caries and students suffering with dental pain caused by 
dental disease. A school nurse acts as a liaison between home and school. A school nurse has the education and skills to recognize unmet dental health needs, is an advocate for the student, is familiar with the community's resources and aware of barriers in accessing care, and can assist families in accessing dental care (Katz \& Stanton, 2003, Scanlan, 1991).

\section{Background/Literature Review}

There is extensive literature examining the dental needs of children and adolescents, with a focus on providing preventive programs for children of elementary school age and younger. Heneghan and Malakoff (1997) reported on the results of a survey sent to 221 principals of "Schools of the 21 st Century" to determine the availability of the schools' health services to evaluate the dental health needs of the schools' populations. The information was used to plan and develop a health component of the "Schools of the $21^{\text {st }}$ Century." Approximately $90 \%$ of the respondents stated that chronic medical and dental problems were prevalent in their schools. About $43 \%$ reported that dental screening was available, but the remaining $57 \%$ reported only monthly or yearly availability of dentists for screening in the schools. School nurses were available at $75 \%$ of the schools and $33 \%$ reported no on-site school nurse.

In a qualitative study conducted in Manchester, England, researchers Preston, Davies, and Craven attempted to investigate parental attitudes, knowledge, behavior, and beliefs toward dental screenings in schools (2001). Dental screenings were performed by a trained dental officer. Letters were sent home describing the results of the screening which included no visible presence of disease to presence of caries, untreated trauma, or heavy calculus deposits. Parents of these children were invited to attend discussion groups and offered monetary incentives. After a series of focus groups, 2 groups of parents were identified for participation in the next phase of the investigation. One group was composed of parents whose children had no visible or symptomatic dental problems, had received a dental letter following the initial screening, and had been taken for regular dental check-ups after the initial screening. The second group consisted of parents of those children who did not follow-up with a dental exam and whose 
children showed symptoms of dental disease. A few parents in the first group felt the screening procedure was invasive and inappropriate and believed it was not the responsibility of the school's but solely of the parents. However, the majority of both groups agreed that dental screening in the school setting was valuable and some parents admitted that they relied on the school screening as their only source of dental care. Interestingly, parents from both groups felt that after about age 7 years, the responsibility for dental health belonged to the child. Parents admitted that this feeling was due to the enormous struggles between parent and child in their attempts to get their children to continue practicing oral hygiene, such as regular teeth brushing. Two important findings from this study revealed that (a) many parents do not understand that good dental hygiene during childhood contributes to the overall health and well-being of the child, and (b) that parents do not consider the health of the primary teeth as important as the health of the secondary teeth.

Yu, Bellamy, Schwalberg, and Drum (2001) examined demographic and other factors that affect access to and need for preventive dental health services in the adolescent population (2001). Yu et al. (2001) used the existing data from the National Longitudinal Study of Adolescent Health (NLSAH) (Udry \& Bearman, 1998) that is from a nationally representative sample of 5,644 adolescents based on self- and parent-reported data (Udry \& Bearman, 1998). Yu et al. (2001) used only the self-reported portion of the data from the NLSAH on the use of medical and dental services.

The study analyzed four intervening dependent variables. The four variables were:

(a) adolescents who had a physical exam within the last year, (b) adolescents who had never had a physical exam, (c) adolescents who had a dental exam within the last year, and (d) adolescents who had never had a dental exam. Two of the variables were especially critical in examining oral health outcomes. Health insurance and family income had the most impact on adolescents' use of dental services. Greater than half of uninsured teens reported not having had an annual dental visit compared with about $25 \%$ of those adolescents who did have dental coverage. It was also noted that there was an association with the race/ethnicity, place of birth, 
and education of the parents to those adolescents who did not have either annual visits or any dental care. The two groups who were least likely to have ever had a dental exam were adolescents of Hispanic immigrant parents and black or mixed race/ethnic adolescent males.

Vargas et al. (2003) documented and compared the status of oral health among children and teens from urban and rural areas. The findings were based on existing data collected from the third National Health and Nutrition Examination Surveys (NHANES III) (U.S. Department of Health and Human Services, 1996). The variables examined were dental health insurance, perception of dental health, use of dental services, and status of oral health. Children living in rural areas were less likely to have dental health insurance than the children living in urban areas. A higher percentage of children in rural areas reported unmet dental needs and the use of dental services was significantly lower among the rural children. Finally, poor children living in rural areas had fewer dental visits than poor children living in urban areas. Vargas et al. noted that the data point to the importance of understanding and addressing the disparities that exist between these socio-geographic areas.

Between 1997 and 2001, public health dental hygienists performed a massive dental health screening in all the elementary schools within the Capital Health District of Nova Scotia (Chalmers, 2003). The main purpose of the screenings was to identify all high-risk populations of students within the schools who would then be eligible for a fluoride mouth rinse program. A secondary purpose was to use the data to develop other health strategies that would address the problem of chronic dental disease. There was a high percentage of students with untreated decay and there were many students who had not visited a dentist within the previous year, even though children younger than 10 years of age had universal access to a publicly-financed dental plan, the Children's Oral Health Program (C.O.H.P).

Following the initial screenings, a school with a population that had a high percentage of untreated dental decay was targeted for a pilot project to help address these issues. Two more screenings were then conducted by public health dental hygienists a year apart to determine if modifications in the dental program improved the oral health and increased dental visits. The 
modifications consisted of an increased outreach effort to parents and encouraging participation in the screening program. Results showed a decrease in decay and an increase in dental visits. However, it was also noted that more research was needed to address the disparities that existed. For instance, the children of parents with higher education levels had a lower mean number of decayed, missing, or filled surface (dmfs) than the children with parents of lower education.

Peterson \& Lopez et al. (1999) conducted a survey in Texas public schools to identify the dental needs of the students. A questionnaire was mailed to approximately 2,000 school nurses, asking them to describe the types and frequencies of dental problems observed in their schools. According to Peterson et al. (1999), 54\% responded, reporting that about $3.5 \%$ of the students who visited the nurse had complaints of dental pain or discomfort. Twelve of the respondents reported that over half the visits to the nurse's office were related to dental problems. The limitations of this study were that the nurses had to rely on their recollections of the number of visits made concerning dental needs and not on a specific measurement of how many students had dental problems. Secondly, not all students with dental pain reported to the nurse's office. Thus, some students with dental disease may never have visited the nurse with dental complaints. Further, Peterson et al. stated that to obtain an accurate account of the frequency and types of dental morbidity, a complete exam is needed, including x-rays, by a dentist or dental professional. Finally, they believed that an oral health screening is valuable only if resources can be provided for follow-up dental treatment.

Freire, Hardy, and Sheiham looked at the impact of the home environment on dental behaviors and practices (2001). Using the salutogenesis theory, a psychosocial approach, as a framework for their investigation, they looked at the correlation of the mothers' sense of coherence (SOC) with the dental health behaviors of their children. SOC is defined as the ability and extent one has to maintain confidence. In this context, the researchers compared the SOC of the mothers of 644 teens in Brazil with the oral health of their children. The SOC of the mothers was measured using a short version of the SOC scale, developed by Antonovsky (1987). The 
questionnaire addressed several oral health behaviors (a) the presence and degree of dental caries, (b) daily oral hygiene habits, (c) utilization of dental attention (visits to dentist for either regular check ups or for emergencies only), and (d) sugar intake. The findings showed that mothers with a high level of SOC were associated with adolescents who had lower levels of dental caries and periodontal disease and regular dental visits.

\section{Theoretical Perspective/Conceptual Framework}

The purpose of this study was to examine the prevalence of dental caries in a specific adolescent population to (a) identify the high risk adolescents, and (b) identify possible contributing factors to dental health issues. One of the theories that provides a framework for the practice of health promotion is the Health Belief-Model (Rosenstock, 1990). Rosenstock developed this model to help explain the reasons people do not practice preventive health behaviors. This model attempts to explain how and why people practice certain health behaviors and the factors that are responsible for changing these behaviors to promote better health practices. The key elements in this model are (a) the presence of perceived susceptibility, (b) perceived severity, (c) perceived benefits, (d) perceived barriers, (e) cues to action, and (f) selfefficacy.

The health belief model provides a framework to examine issues related to lack of preventive dental treatment. Often parents do not see the child as being susceptible to dental caries because they may believe that daily dental hygiene is sufficient and assume the child is taking responsibility for maintaining oral care. During pre-school and school years, parents often leave the responsibility of oral hygiene in the hands of their children to avoid conflict. Additionally, it is less likely that parents even view the child's teeth on a regular basis, thus dental caries are easily overlooked until the cavities become advanced enough to cause pain and difficulty chewing. Unfortunately, even when a child has noticeable dental caries, the parent does not fully appreciate the serious nature and potential consequences of poor oral health. Parents/caregivers may be cognizant of the fact that the child has dental decay but not realize the 
damaging effect on overall health. Some parents/caregivers do not take dental health seriously because they know that the permanent, or secondary set of teeth will eventually replace the "baby" teeth.

\section{Methodology}

Research Design

A descriptive study design was used to examine the question, what is the prevalence of dental caries in students from a California Central Coast middle school in an area where the water is not fluoridated. Existing data was analyzed to determine the prevalence of dental caries in the participant population. Means and percentages were used to determine the at risk groups. The school site administrator and the San Jose State University (SJSU) Human SubjectsInstitutional Review (IRB) approved the study. The data to be analyzed was pre-existing data.

For the purposes of this study specific terms were defined. Poor was defined as a family income at or below $100 \%$ of the federal poverty level (FPL) and near poor was defined as a family income of 101 to $200 \%$ of the FPL. Decayed, missing, and filled surfaces were specified as dmfs. The status of dental caries was defined by classifications provided by the local professional dental society:

Class I: No visible caries

Class II: May need to see dentist, possible dental caries

Class III: Significant caries visible

Class IV: Advanced dental caries, abcess with or without pain, emergency dental attention needed

\section{Participants}

A convenience sample of 526 students from a California Central Coast middle school, who were $6^{\text {th }}, 7^{\text {th }}$, and $8^{\text {th }}$ graders composed the participant groups. The ethnicity of the total school population included African-American, Hispanic, White, Asian, South Pacific Islander, Filipino, Middle Eastern, Native American Indian, and mixed ethnicity/race (Table 2). 
Approximately $27 \%$ of the students were from families associated with the military.

The socioeconomic status ranged from poor, near poor, at or above the poverty line, to middle and high income, based on the percentage of students who qualified for reduced or free lunch. The education level of the parents ranged from little or no education to advanced degrees.

Setting

The setting was a suburban California Central Coast middle school. It was located on a former United States Army base that is in use to house military families but is no longer an active military base. Neither the middle school nor the families whose children attend the middle school have fluoridated water. The data was accessed and reviewed by the researcher in the school office at predetermined scheduled times.

Research Procedures

The existing data were the results from a dental screening performed by the school nurse during the 2002-2003 school year. The results from all the students $(\mathrm{N}=526)$ were reviewed. Those students with visible caries $(n=30)$, class III or IV, were identified to determine the prevalence of dental caries.

A class roster with results of the dental screening, obtained with permission by the school, was made available to the researcher. Confidentiality was maintained, so that no identifying data could be ascertained, by entering the data on a spreadsheet without names. Students were assigned code numbers. Access to the names of the students was also kept confidential, in a locked file, and known only to the school nurse and this researcher. The data was reported and analyzed as grouped data.

Results

In the 2002-03 school year 5.7\% (Table 5) of the entire school population of a California Central Coast middle school was found to have visible, severe caries. As seen in Table 3, the presence of dental caries in boys and girls was not significantly different $(6.3 \%$ of boys and $5.0 \%$ of girls). There was also no significant difference in the presence of dental caries among the 
three grades as shown in Table $1\left(5.1 \%\right.$ of $6^{\text {th }}$ graders, $7.2 \%$ of $7^{\text {th }}$ graders, and $4.7 \%$ of $8^{\text {th }}$ graders).

However, there was a significant variation between two ethnic groups as shown in Table 4 (4.0\% of non-white students had dental caries compared with $1.7 \%$ of white students). There were twice as many Hispanic students with dental caries as white students $(2.9 \%$ Hispanic students compared with $1.7 \%$ white students). This rate indicates approximately one of 12 Hispanic students had dental caries compared with 1 of every 20 White students who had dental caries. The prevalence of dental caries in African Americans was significantly lower than in Whites $(0.6 \%$ compared with $1.7 \%)$. Approximately $3 \%$ of the 30 students identified with class III or IV dental caries were from immigrant families. Students with parents associated with the military (approximately $27 \%$ of total $\mathrm{N}=526$ ) had no visible caries.

\section{Discussion}

In a California Central Coast middle school during the 2002-03 school year the school nurse performed a dental screening on boys and girls in $6^{\text {th }}, 7^{\text {th }}$, and $8^{\text {th }}$ grades. The ethnic groups included Filipino, Asian, American Indian, Pacific Islander, Hispanic, Black, and White students. Severe visible dental caries were found in five of the ethnic groups. There was little variation between the boys and girls and among the grade levels. The Black or African American segment demonstrated a low prevalence of dental caries. This finding was inconsistent with data found in the literature. The low prevalence may be a result of more of the African American students being associated with the military. However, data related to the percentage of African American students associated with the military was unavailable.

There was significant ethnic variation between the white and non-white (excluding African American) populations of students, particularly in the Hispanic segment. According to these findings, twice as many Hispanic students had dental caries in comparison to white students. Of the 30 students with dental caries, 17 were from immigrant families. The severely advanced state of dental caries points to a lack of attention to dental health factors or issues 
which could include access to health care, proper nutrition, proper oral hygiene, acceptability of health care, or perceived values of health care.

The study findings are especially critical for the non-white population of adolescents. Many of the Hispanic families in the United States (U.S.) are undocumented aliens earning minimum wage as unskilled laborers. They are trying to support not only family members residing in the U.S., but are often sending a portion of their wages to family members living in their native country. As a result of the high cost of health care and health insurance, most immigrant families are unable to afford dental or medical coverage, as well as preventive dental treatment. The water in this area is not fluoridated so prevention measures the community could provide are not available. The immigrant families are often hesitant to apply for governmental insurance programs for their children, such as Medi-Cal (Medicaid) or Healthy Families because they believe that their efforts to obtain United States (U.S.) citizenship may be impeded or jeopardized. They mistrust the government system and refuse to apply for federally or statefunded insurance, even when their U.S. born children would qualify and would not impact the parents' attempts at obtaining U.S. citizenship. The attitudes and beliefs of immigrant parents may indicate a need for increased education of this population concerning available state and federal insurance resources.

There is also a segment of the population whose income falls barely above the poverty level that precludes their qualification for government-funded health care insurance. These families in a lower socio-economic group are the ones who fall through the cracks in the system and will usually seek care only for medical or dental emergencies. The families who are above the poverty level and for whom culture, language, and transportation may not be barriers often lack a higher education which keeps them in lower paying unskilled labor positions and prevents them from improving their standard of living and from affording health coverage. Studies have shown that education, socioeconomic status, and race/ethnicity are factors which often correlate with little or no access to dental care and health care, in general, with proper nutrition and dental 
hygiene, with perceived value of health care, and with acceptability of health care (Feinberg, Swartz, Zaslavsky, Gardner, \& Walker, 2002; Watson et al., 2001).

Another barrier in obtaining adequate dental care is the inadequate number of dentists who participate in governmentally funded insurance programs. Often families must drive long distances to receive care from the dentists who do accept Medi-Cal (Medicaid) and/or Healthy Families. California Kids, a state-funded, low cost medical and dental insurance developed especially for non-U.S. born children, is no longer accepting new applications. The avenues for dental care for the undocumented are severely limited. In the surrounding area of the middle school involved in this study, the few dentists who accept Medi-Cal, Healthy Families, and California Kids are located in outlying towns and cities. Many of the immigrant families are undocumented and unable to own cars or gain access to adequate transportation.

The findings in this study and data from the literature review may indicate a significant difference in health care and other health related factors in the racial and ethnic minority population of adolescents. Governmental officials and political figures need to be made aware of such findings by health care professionals and community members.

The literature provided extensive support for identifying the prevalence of dental caries and oral health problems in the adolescent population. Besides the identification of ethnicity and socio-economic status as contributing factors to lack of dental care and and existence of dental disease, the water in this area is not fluoridated so prevention measures the community could provide are not available.

\section{Limitations}

This study used a convenience sample and was not representative of the U.S. middle school population. Thus, the findings cannot be generalized to the population of adolescents in middle schools. Additionally, the middle school involved in the study was not representative of the average American middle school due to the high number of military families whose children attended the school. Military families are provided with excellent medical and dental coverage. 
Therefore, students of military families were less likely to have unmet dental needs because the parents have the means to provide their children with a nutritious diet, regular health care, practice preventive dental health care including brushing, flossing, and access to professional dental care for teeth cleaning, fluoride treatments, and regular check ups.

Another limitation of the study was the unavailability of data regarding the percentage of African American children associated with the military. Further, a large number of immigrant students fell into the lower socio-economic group, had no medical coverage, and thus were more likely to have unmet dental treatment needs.

\section{Recommendations}

In order to ascertain a more representative population and provide a larger database, it would be important to examine a larger sample and include analyzed dental screening results of the other middle schools in this district. Further, more research is needed to examine the prevalence of dental caries in African-Americans whose families are associated with the military compared to those who are not.

In areas where the water system is not fluoridated, the school nurse can work with other health care providers, especially in dentistry, to promote the fluoridation of water in the area. Identifying at risk populations in communities who could benefit from dental health promotion and fluoride treatment programs is another area of recommended research.

Presenting dental screening statistics/findings/results to school boards, community service organizations, state politicians, and governmental officials, informs them of the differences in health care that exist in the adolescent population. Researching, maintaining, and analyzing statistical data related to health screening outcomes provides ongoing documentation of student health care needs.

Examining the health practices related to diet, dental hygiene practices, and dental care history of the adolescent population in this study would provide data to identify possible points of intervention. Additional research on each of the health care practice areas related to the 
immigrant population is also needed to assist in more appropriate health care interventions, especially in the school setting, and identify possible links to dental health problems.

\section{Implications for School Nursing}

The role of the school nurse is crucial in the provision of school health services. Dental screenings performed by the school nurse are of utmost importance because, for many students, the school nurse is the only healthcare professional with whom they come into contact. Within the boundaries of the school setting, the school nurse can identify and help meet the student's dental needs that can have an impact on academic achievement. The school nurse is able to assess the student's oral health status, teach preventive dental health education, and provide community resources for students who lack access to dental care. From the perspective and developmental level of the adolescent, much attention is given to outward appearance and less to healthy behaviors. In providing dental health education the school nurse can stress the appeal of clean healthy teeth and fresh breath that would probably impress the adolescent who wants to look his/her best. Dental screenings performed by the school nurse provide an excellent venue for accomplishing the goal of promoting dental health care in students and encouraging preventive dental hygiene practices.

Many elementary schools have dental hygiene programs initiated by the school nurse, in conjunction with a dental clinic or local health department. Such dental hygiene programs which include daily teeth brushing and fluoride rinsing are often part of the health curriculum in the primary grades (Chalmers, 2003, Mortality and Morbidity Weekly Report [MMWR], 2001). Similar dental hygiene programs could be incorporated into the health curriculum in middle schools. The school nurse can also provide research-based evidence of the positive correlation of dental sealants and decreased dental caries. School nurses can acknowledge the parents who instill healthy behaviors in their children and encourage them to share successes with other parents during health forums, health fairs held at school and via school newsletters. 
School nurses are aware of parents who wait until their child is experiencing dental pain or is having symptoms of an oral infection before seeking dental treatment. It is not uncommon for many parents to view poor dental health as a disease condition of lesser importance. Parents may not know that diseased primary teeth can have a deleterious effect on the unerupted secondary dentition, and on speech, and can negatively impact overall health by causing a systemic infection. Parents may not realize that the pain and discomfort of dental disease can interfere with the student's ability to concentrate on academics. Parents may be unaware of their child's dental caries because of the relatively slow progression of dental decay. Educational dental health outreach programs that promote healthy life styles and enlighten parents about the detrimental effects of dental disease and the long-lasting benefits of preventive dental health practices is crucial. When parents acquire knowledge about the deleterious effects of dental caries on overall health and the benefits of oral health on the student's pursuit of academics, they may find it easier to accept the concept of preventive dental health and encourage this behavior in their children.

The greater prevalence of dental caries in the immigrant Hispanic and poor populations has significant implications for school nursing. Research studies have shown that children of immigrant Hispanic families and children in families with incomes at the poor and near poor FPL are least likely to have any medical or dental insurance. School nurses should be aware of community resources such as the Child Health and Disease Prevention (C.H.D.P.) Gateway Program that targets children with no medical coverage and financial need. This program offers free or low cost physical exams during which a child with unmet dental needs can receive a dental referral for no or low cost dental treatment. The school nurse is in a position to be an advocate for the underserved students with unmet dental needs and inadequate health care resources.

Families are often confronted with a number of barriers that preclude obtaining dental treatment. The barriers include a lack of financial resources, health coverage, time for dental appointments, an insufficient number of dentists who accept state or federally funded insurance, 
poor or inadequate dental behaviors in the home, and lack of parents' ability to enforce self-care. The school nurse can collaborate with local community health clinics, social service organizations, and health educators to assist families in accessing health care and, thus, overcoming many of the obstacles to obtaining healthcare. The school nurse can facilitate parents' access into the healthcare system and make sure follow-up dental treatment is obtained. Community agencies must network with service and healthcare organizations to form collaborative groups that work to address the needs of the families who are unable to afford outof-pocket dental expenses, yet who have an income level that precludes qualifying for government health insurance programs.

Parents may be aware of the health risks of dental disease and the importance of preventive care, but aside from the lack of financial resources, health care coverage, and available dentists, they are confronted with other barriers. Parents working long hours have difficulty getting time from work for dental appointments. Many families have no reliable mode of transportation and must rely on mass transit, extended family members, or friends. Funding from Healthy Start grants and hospital donations have enabled some school districts to provide mobile dental clinics thus reaching the families who lack transportation.

There is a need for school site dental screenings by school nurses and analysis of data to identify populations at highest risk, determine risk factors, and develop appropriate intervention strategies. Through educational outreach programs that promote and reinforce healthy lifestyles, school nurses can help families acknowledge the existence of a dental health problem, understand the severity of it, learn the benefits of dental healthcare, and offer support in accessing and utilizing dental healthcare.

Tables [see attached document] 


\section{References}

American Academy of Pediatric Dentistry. (n.d.). Regular dental visits. Retrieved July 16, 2004, from http://www.aapd.org

Amsler, D. H. (2003). A hidden epidemic: dental disparities among children. Journal of School Health, 73(1), 38-41. Retrieved September 20, 2003 from CINAHL: http://libaccess.sjsu.edu:2066

Antonovsky, A. (1981). Health, stress, and coping (3rd ed.). London: Jossey-Bass.

Centers for Disease Control. (2002). National Center for Chronic Disease Prevention and Health Promotion. Retrieved November 9, 2003, from U.S. Department of Health and Human Services Web Site: http://www.cdc.gov/OralHealth/factsheets/dental_caries.htm

Chalmers, D. (2003). An enhanced screening and referral program. Probe, 37(1), 35-7.

Dental Health Foundation (2001). The oral health of California's children: halting a neglected epidemic. Canadian Dental Health Association, 16(1), 24-27.

Feinberg, E., Swartz, K., Zaslavsky, A., Gardner, J., \& Walker, D. K. (2002). Family income and the impact of a children's health insurance program on reported need for health services and unmet health need [Electronic version]. Pediatrics, 109, 1-10. Retrieved August 30, 03 from CINAHL: http://libaccess.sjsu.edu:2166/ovidweb.cgi

Freire, M., Hardy, R., \& Sheiham, A. (2002). Mothers' sense of coherence and their adolescent children's oral health status and behaviours. Community Dental Health, 19(1), 24-31.

Heneghan, A. M., \& Malakoff, M. E. (1997). Availability of school health services for young children [Electronic version]. Journal of School Health, 67, 327-32. Retrieved September 1, 2003 from CINAHL: http://libaccess.sjsu.edu:2166/ovidweb.cgi

Katz, Deborah, \& Staton, Allison (2003). Community approaches to a national problem: Oral health. School Nurse News, 20(4), 40-42.

Monterey Bay Dental Society. (n.d.). Monterey Bay Dental Society. Retrieved September 1, 2003, from California Dental Association Web Site: http://mbdsdentists.com/ 
Morbidity and Mortality Weekly Report. (2001, August 31). Impact of targeted, school-based dental sealant programs in reducing racial and economic disparities in sealant prevalence among schoolchildren--Ohio, 1998--1999. Retrieved November 9, 2003, from Centers for Disease Control Web Site: http://www.cdc.gov/mmwr/preview/mmwrhtml/mm5034a2.htm

Peterson, J., Niessen, L., \& Lopez, G. M. (1999). Texas public school nurses' assessment of children's oral health status. Journal of School Health, 69, 69-72.

Preston, S. T., Davies, G. M., \& Craven, R. (2001). An investigation of parents' attitudes to dental health and school dental screening. Community Dental Health, 18, 105-109.

Rosenstock, I. M. (1990). The health belief model: Explaining health behavior through expectancies. In K. Glanz, F.M. Lewis, \& B.K. Rimer (Eds.), Health behavior and health education: Theory, research, and practice (1st ed., pp. 39-62). San Francisco: JosseyBass.

Scanlan, Betty J. (1991). An holistic approach to school dental health. Journal of School Nursing, 7(4), 12-15.

U.S. Department of Health and Human Services (DHHS) (1996). National center for health statistics. Third national health and nutrition examination survey, 1988-1994, NHANES III laboratory data file (CD-ROM) [CD-ROM]. Abstract from: NHANES III Laboratory Data File (CD-ROM). Public Use Data File Documentation Number 76200. Hyattsville, MD: Centers for Disease Control and Prevention, 1996.

U.S. Department of Health and Human Services. (2000). Healthy People 2010 2nd ed. [Electronic version] Retrieved September 6, 2003, from http://www.healthypeople.gov/document/word/Volume2/210ral.doc

Udry, J. R., \& Bearman, P. S. (1998). The national longitudinal study of adolescent health. [Electronic version] Retrieved September 3, 2003, from Add Health Study, Research Design Web Site: http://www.cpc.unc.edu/addhealth/designfacts 
Vargas, C. M., Ronzio, C. R., \& Hayes, K. L. (2003). Oral health status of children and adolescents by rural residence, United States. Journal of Rural Health, 19(3), 260-8.

Watson, M. R., Manski, R. J., \& Macek, M. D. (2001). The impact of income on children's and adolescents' preventive dental visits. Journal of the American Dental Association, 132, $1580-7$.

Yu, S. M., Bellamy, H. A., Schwalberg, R. H., \& Drum , M. A. (2001). Factors associated with use of preventive dental and health services among U.S. adolescents. Journal of Adolescent Health, 29, 395-405. 
Table 1. Prevalence of Dental Caries Among Sample Population in $6^{\text {th }}, 7^{\text {th }}$, and $8^{\text {th }}$-Grade Students in 2002-2003

\begin{tabular}{lccc}
\hline & $\begin{array}{c}6^{\text {th }} \text { Grade } \\
\mathrm{N}=176 \\
n(\%)\end{array}$ & $\begin{array}{c}7^{\text {th }} \text { Grade } \\
\mathrm{N}=180 \\
n(\%)\end{array}$ & $\begin{array}{c}8^{\text {th }} \text { Grade } \\
n(\%) \\
\mathrm{N}=170\end{array}$ \\
\hline Presence of visible caries & $9(5.1)$ & $13(7.2)$ & $8(4.7)$ \\
No visible caries & $167(94.9)$ & $167(92.8)$ & $162(95.3)$ \\
\hline
\end{tabular}

Table 2. Ethnicity in a California Central Coast Middle School in 2002-03

\begin{tabular}{lc}
\hline & $\mathrm{N}=526$ \\
Ethnicity & $\mathrm{n}(\%)$ \\
\hline African American & 18.5 \\
Asian American & 4.6 \\
Hispanic & 32.4 \\
Filipino & 6.3 \\
Pacific Islander & 2.6 \\
American Indian & 0.5 \\
White & 35.0 \\
\hline
\end{tabular}

Table 3. Prevalence of Dental Caries Among Sample Population $6^{\text {th }}, 7^{\text {th }}$, and $8^{\text {th }}$-Grade Boys and Girls in 2002-2003

\begin{tabular}{lcccc}
\hline $\begin{array}{c}6^{\text {th }} \text { Grade } \\
n(\%)\end{array}$ & $\begin{array}{c}7^{\text {th }} \text { Grade } \\
n(\%)\end{array}$ & $\begin{array}{c}8^{\text {th }} \text { Grade } \\
n(\%)\end{array}$ & $\begin{array}{c}\text { Total } \\
n(\%)\end{array}$ \\
\hline Girls & $6(6.2)$ & $3(3.4)$ & $4(5.5)$ & $13(5.0)$ \\
Boys & $3(3.8)$ & $10(11.1)$ & $4(4.1)$ & $17(6.3)$ \\
\hline
\end{tabular}

Table 4. Prevalence of Dental Caries Among Sample Population $6^{\text {th }}, 7^{\text {th }}$, and $8^{\text {th }}$-Grade Students by Ethnicity in 2002-2003

\begin{tabular}{lllcc}
\hline & $\begin{array}{c}6^{\text {th }} \text { Grade } \\
n(\%)\end{array}$ & $\begin{array}{c}7^{\text {th }} \text { Grade } \\
n(\%)\end{array}$ & $\begin{array}{c}8^{\text {th }} \text { Grade } \\
n(\%)\end{array}$ & $\begin{array}{c}\text { Total } \\
n(\%)\end{array}$ \\
\hline African American & $0(0)$ & $2(1.1)$ & $1(0.6)$ & $3(0.6)$ \\
Hispanic & $6(3.4)$ & $3(1.7)$ & $6(3.5)$ & $15(2.9)$ \\
Pacific Islander & $0(0)$ & $1(5.6)$ & $0(0)$ & $1(0.1)$ \\
Vietnamese & $2(1.1)$ & $0(0)$ & $0(0)$ & $2(0.4)$ \\
White & $1(0.6)$ & $6(3.3)$ & $1(0.6)$ & $9(1.7)$ \\
\hline
\end{tabular}


Table 5. Prevalence of Dental Caries Sample Population in White and Non-White Students in 2002 and 2003 White

$n(\%)$ Non-White $n(\%)$

Presence of visible caries

$9(1.7)$

$21(4.0)$ 